\title{
A regra da maioria como agregação de preferências: questões e respostas
}

\author{
Palavras-chave \\ agregação de preferências, \\ regra da maioria, \\ questões, respostas

\section{Classificação JEL} \\ D7, D72, D79

\section{Keywords \\ preference aggregation, majority rule, questions, answers}

\section{JEL Classification}

D7, D72, D79

\section{Resumo}

Ancorado na abordagem racionalista, mas na impossibilidade da regra consensual e buscando apresentar as características da regra da maioria e alguns de seus problemas, como o paradoxo de Condorcet, e soluções a esses problemas, como o logrolling, este artigo se propõe a revisar e sintetizar a teoria a respeito, baseado nas principais contribuições ao tema. $\mathrm{O}$ estudo se justifica porque, como processo de agregação de preferências, a regra da maioria se destaca para usos eleitorais e de processos políticos internos, em um elevado número de nações.

\author{
Arnaldo Mauerberg Junior* \\ Eduardo Strachman ${ }^{\star *}$
}

\section{Abstract}

Anchored in the rationalist approach, but with the impossibility of consensus rule and seeking to show the characteristics of the majority rule and some of its problems, as the Condorcet paradox, and solutions to these problems, such as logrolling, this article intends to review and synthesize theory about it, based on the main contributions to the theme. The study is justified because, as a process of preference aggregation, majority rule is used for election purposes and internal political processes in a large number of nations. 


\section{1_Introdução}

Atualmente, alguns Estados são mais democráticos e outros menos, alguns mais liberais, outros nem tanto, o fato é que o Estado se faz presente em todos os países conhecidos. Segundo Hardin (1997), a existência do Estado se justifica por três motivos: a oferta de bens públicos, a coordenação entre os agentes e a manutenção de uma evolução estável; já para Mueller (1997), os governos surgem para diminuir os custos de transação em uma sociedade composta de inúmeros agentes, enquanto, de acordo com Ostrom e Walker (1997), essas estruturas emergem para resolver problemas de ação coletiva.

Segundo Brady, Seldon e Tullock (2005), autores e defensores da Escola da Escolha Pública, o governo pode ser comparado com um agregador das vontades individuais de agentes autointeressados. Tal hipótese, mesmo sendo criticada por visões que tratam o Estado como uma entidade ultracomplexa, como determinados ramos da Ciência Política, não desmerece a contribuição seminal daquela Escola de Pensamento.

Estudos originais dentro da teoria econômica com foco na análise do Estado e de seus integrantes foram feitos por Downs (1999 [1957]), que introduz o autointeresse presente nos agentes econômicos também nos membros do governo. Adotando essa principal premissa de Downs, a do autointeresse dos agentes, Buchanan e Tullock (1990 [1962]) desenvolveram uma teoria para a análise das regras de votação. Ainda nessa linha de estudos comportamentais sobre agentes públicos, Olson (1971 [1965]) nega a teoria convencional dos grupos, afirmando que as pessoas só os procuram se esperam ter algum retorno individual, contradizendo assim autores pluralistas, como Latham, Bentles e Truman, que contestam os interesses individuais, afirmando que a ação gira sempre em torno da coletividade.

Uma vez que a existência de Estados, atualmente, é um fato, e que os componentes dessas estruturas possuem comportamentos distintos, explicados por diversas escolas de pensamento, analisaremos alguns meios pelos quais os agentes públicos podem tomar decisões e votar. Existem inúmeras formas para isso, sendo os processos eleitorais mais conhecidos os sistemas de eleição majoritários e proporcionais. Neste sentido, temos observado recentemente um debate referente à manutenção do voto proporcional ou à adoção do sistema majoritário (voto distrital), para as eleições legislativas no Brasil. Ambos os sistemas possuem vantagens e limitações, remetendo à necessária existência do Estado, em sociedades modernas. Dentro desse debate, buscamos analisar as propriedades teóricas da regra da maioria como sistema eleitoral e de escolha em processos políticos internos, como votações em comitês, etc.

Empiricamente as vantagens e as desvantagens dos sistemas majoritários já foram apresentadas por diversos estudos empíricos, como os de Nicolau (2004) e Lijphart (2011). ${ }^{1}$ Para Nicolau, processos majoritários (como os praticados nos EUA, no Reino Unido e no Canadá) geram maior proximidade do eleitor com seu representante, não requerem a formação de uma grande coalizão de governo - uma vez que favorecem a extinção de pequenos partidos mas podem implicar a penalização a partidos com votação expressiva, mas dispersa.

Duverger (1964) apresenta o aparecimento de dois efeitos em sistemas majoritários: o efeito mecânico e o efeito psicológico. No primeiro, observa-se a tendência de que todos os partidos, com exceção dos dois maiores, tendem a ficar sub-representados, obtendo menos cadeiras do que o efetivamente apurado. $\mathrm{O}$ segundo efeito atesta que os eleitores, sabendo que os partidos menores não possuem chances, não "desperdiçariam" seus votos, votando apenas nas duas maiores siglas. Isso levaria a um ciclo vicioso tendendo à extinção dos pequenos partidos. ${ }^{2}$ 
Corroborando as proposições de Duverger (1964), Lijphart (2011) mostra que um aumento de 5\% na desproporcionalidade do sistema eleitoral (gerado pela regra da maioria) leva a uma diminuição de 0,52\% no número efetivo de agremiações políticas. Afirma ainda que um sistema majoritário tende a um gabinete de maioria mínima, centralizado e unitário.

A despeito das valiosas contribuições empíricas fornecidas pelos autores supracitados, neste artigo buscamos sintetizar e esquematizar as propriedades do processo de votação por maioria, algumas de suas falhas inerentes, possíveis soluções e, dentro dessas soluções, argumentos que possam manter tal processo de escolha pela maioria. Como possível solução de falhas, encontra-se o logrolling e a defesa dessa prática, através de teorias que procuram demonstrar que, dadas certas condições (estabilidade das coalizões, por exemplo), ela proporciona um benefício agregado à população. Para isso, realizamos uma revisão da literatura sobre 0 assunto, buscando identificar as bases teóricas que explicitam os problemas da regra da maioria e suas potenciais soluções.

$\mathrm{O}$ artigo se estrutura da seguinte forma: a primeira seção apresenta as características da regra da maioria e alguns problemas que a escolha dessa forma de decisões coletivas pode gerar. Posteriormente, na segunda seção, apresentamos o conceito de troca de votos e a solução que ela fornece para determinados problemas oriundos da utilização da regra da maioria. A terceira seção familiarizará o leitor com algumas teorias que saem em defesa da estabilidade das coalizões partidárias e, por conseguinte, dos benefícios do logrolling. Nas considerações finais, apresentamos os principais pontos de destaque pertinentes à análise.

\section{2_A regra da maioria}

Esta seção aborda a questão da votação baseada na regra da maioria, utilizada nos sistemas de agregação de preferências em diversos países e atividades. Definida por Austen-Smith e Banks (2000), em um ambiente onde: dado $\Gamma$, um conjunto finito de alternativas, $\forall a, b \in \Gamma, a P b$ se, e somente se, $|P(a, b ; \rho)|>n / 2$, com $\rho$ sendo o conjunto capaz de descrever a preferência de todos os indivíduos, $n$ o número de agentes envolvidos no processo, e $P$ denotando a existência de preferência.

Pensando, então, em uma regra de maioria simples $(50 \%+1)$, certas pessoas envolvidas na votação nitidamente podem obter resultado indesejado, com a apuração final do processo. Isso porque nem todos pensam ou manifestam seus desejos da mesma maneira. Buchanan e Tullock (1990 [1962]) afirmam que uma regra de maioria inevitavelmente impõe a uma minoria vencida que aceite determinadas ações e não possa pedir compensações por isso. Temos aqui, portanto, 0 conceito de externalidade. Ou seja, desde que é obrigada a aceitar um resultado indesejado, sem poder obter algum reparo por isso, a minoria vencida se encontra após a votação em uma situação pior do que se encontrava antes desse processo - a regra da maioria acaba gerando uma externalidade negativa para os perdedores. Os autores mostram, então, que o único processo de agregação de preferências capaz de gerar zero de externalidades é a regra do consenso, ${ }^{3}$ pois, se todos concordam com uma proposta, obviamente o resultado de todos os participantes após a votação será positivo; do contrário, algum agente discordaria, e o projeto em questão não seria aprovado (supondo que a rejeição do projeto gere uma utilidade igual a zero em todos os agentes). Logo, o consenso é uma regra que não gera externalidades negativas aos agentes; ao invés disso, acaba gerando uma sensação de justiça, dado que todos vão pagar pelo que foi aprovado e todos devem se beneficiar de seus resultados. 
Não obstante, esses mesmos autores não negam que essa regra é inviável para uma população de grande tamanho. Os custos para que as decisões sejam aprovadas por toda a população são demasiado grandes: os custos de negociação para que os contrários fossem convencidos pelos favoráveis a um dado projeto seriam extremamente elevados, ou mesmo proibitivos, seja pelo tamanho de determinada região ou país, seja pela barganha em si, com uma população acima de certas proporções. ${ }^{4}$

$\mathrm{Na}$ impossibilidade do consenso, Tideman (1997) apresenta algumas formas para agregar as preferências dos agentes. A primeira, defendida por Wicksell, mostra que, se aumentarmos a proporção necessária de eleitores para aprovar determinada questão, o processo seria mais justo. Entretanto, aqui se pode observar o problema de que o eleitor envolvido pode não fazer um juízo perfeito sobre a questão alvo da votação, dado que, para ele, o seu benefício será sempre maior que o custo dos perdedores, restando aos outros participantes do processo o "ônus" de tal resultado. Sem ainda mencionar que a proposta de Wicksell se aproxima bastante do cálculo consensual (defendendo maior número possível de agentes representativos).

Thompson apresenta outra opção, na qual o perdedor receberia uma espécie de bônus, para cada projeto que fosse contra a sua vontade. Antes da votação, os indivíduos revelariam suas preferências. Após o processo, os "perdedores" receberiam a gratificação referente ao valor da perda gerada pela aprovação do projeto. $O$ problema dessa proposta reside no fato de que pessoas favoráveis à aprovação, cientes da vitória da proposta, poderiam manifestar um desejo pela reprovação, para no final, receber o benefício gerado pelo projeto e o bônus por terem sido contrários à proposta, ou seja, uma parcela da população poderia mentir sobre seu desejo, caso soubesse que o projeto seria aprovado independentemente de seu voto. Tal procedimento pode ser chamado de voto estratégico ou sofisticado.
May (1952, 1953), baseado nos axiomas da decisão (nos quais, para um dado par de alternativas, uma regra deve gerar um resultado único) e da resposta positiva (os votos não podem ser contados de forma contrária), afirma que um procedimento que os obedeça é minimamente eficiente, se ele ainda obedecer aos axiomas do anonimato (se o voto de duas pessoas for trocado, o resultado final não é alterado) e da neutralidade (se as preferências dos indivíduos entre duas opções for a mesma, o resultado final é indiferente, se só existirem essas duas opções); então, tal procedimento também apresentará igualdade política estritamente formal. O Teorema de May afirma que só a regra da maioria é capaz de ser minimamente eficiente e apresentar também uma igualdade política estritamente formal.

Mesmo sendo provado axiomaticamente que a maioria simples é um mecanismo de votação minimamente eficiente e que passa pelo teste da igualdade política estritamente formal, essa regra pode apresentar um sério problema, conhecido como paradoxo de Condorcet, paradoxo do voto, ou intransitividade no agregado das preferências ou ciclos. Esse paradoxo foi analiticamente estudado por Gehrlein (1983). De acordo com Enelow (1997), a regra de maioria pode gerar um vencedor em qualquer circunstância, chamado de "ponto não dominado": desde que não existam ciclos nas preferências dos votantes, esse vencedor é chamado de "vencedor Condorcet", em homenagem ao criador desse método de votação. Vejamos primeiramente um exemplo em que a transitividade é respeitada: pelo método de Condorcet, as escolhas são sempre entre duas alternativas específicas, as preferências individuais estão sempre definidas e são completas, e as alternativas devem ser votadas duas a duas, em etapas, ou seja, o vencedor de uma primeira votação disputará o resultado final com a opção restante. Assim, sendo:
$a P b$
$b P c$
$a P c$ 
onde $a, b$ e $c$ são três alternativas diferentes que estão concorrendo em dada eleição, e $P$ indica a ordem de preferência - assim, na primeira linha, se lê que $a$ é preferido a $b$, e assim sucessivamente -, pelo método de Condorcet, dividindo o processo em um primeiro turno, no qual um par se enfrenta, e o vencedor desse turno prossegue para um segundo, contra o oponente que permaneceu de fora, temos os seguintes resultados:

$1^{\circ}$ turno com $a$ e $b$, e o vencedor enfrentando a no segundo turno: $a$ ganha de $b$ e enfrenta $c$; no segundo turno $a$ ganha de $c$.

$1^{\mathrm{o}}$ turno com $a$ e $c$, e o vencedor enfrentando $b$ no segundo turno: $a$ ganha de $c$ e enfrenta $b$; no segundo turno $a$ ganha de $b$.

$1^{\circ}$ turno com $b$ e $c$, e o vencedor enfrentando $a$ no segundo turno: $b$ ganha de $c$ e enfrenta $a$; no segundo turno $a$ ganha de $b$.

Temos, que graças à transitividade observada anteriormente, a alternativa A vence independentemente da forma como a agenda de votação é montada.

Entretanto, mesmo que as preferências dos agentes sejam transitivas, nada garante que o agregado o será. ${ }^{5} \mathrm{Ob}$ servando primeiramente as preferências individuais e posteriormente o agregado, supondo que existam as mesmas três alternativas, $a, b$ e $c$; e três agentes, $\mathrm{X}$, Y e Z, temos:

Tabela 1_Transitividade individual e intransitividade coletiva

\begin{tabular}{|c|c|c|}
\hline Votação entre a e b & Votação entre b e c & Votação entre a e c \\
\hline$a-2 \operatorname{votos}(X$ e $Y)$ & $b-2$ votos (X e Z) & $c-2$ votos (Y e Z) \\
\hline$b-1$ voto $(Z)$ & $c-1$ voto $(Y)$ & $a-1$ voto $(X)$ \\
\hline
\end{tabular}

Fonte: Wieting Jr. (1966).
Analisando a transitividade dos agentes de forma individual:

$\begin{array}{ccc}\mathrm{X} & \mathrm{Y} & \mathrm{Z} \\ a P b & c P a & b P c \\ b P c & a P b & c P a \\ a P c & c P b & b P a\end{array}$

Vemos que todos os agentes satisfazem o requisito de transitividade. Contudo, podemos observar claramente, na Tabela 1, que o processo acima não apresenta transitividade em uma forma agregada, já que, pelo quadro de resultados de votação, temos:
$a P b$
$b P c$
$c P a$

$\mathrm{O}$ que nitidamente apresenta intransitividade, ou comportamento cíclico. Supondo que a preferência agregada seja ordenada da maneira anteriormente citada, ou seja:
$a P b$
$b P c$
$c P a$

Aplicando o método de Condorcet temos:

$1^{\circ}$ turno com $a$ e $b$, e o vencedor enfrentando $c$ no segundo turno: $a$ ganha de $b$ e enfrenta $c$; no segundo turno $c$ ganha de $a$.

$1^{\circ}$ turno com $a$ e $c$, e o vencedor enfrentando $b$ no segundo turno: $c$ ganha de $a$ e enfrenta $b$; no segundo turno $b$ ganha de $c$.

$1^{\circ}$ turno com $b$ e $c$, e o vencedor enfrentando $a$ no segundo turno: $b$ ganha de $c$ e enfrenta $a$; no segundo turno $a$ ganha de $b$.

Vale dizer, então, dependendo de como o primeiro turno é realizado, o resultado final da votação muda drasticamente, graças à existência de ciclos (ou intransitividade), não existindo a garantia de um vencedor Condorcet no processo. Logo, pode existir a manipulação da agenda de votação por parte dos organizadores do processo em questão. ${ }^{6}$ 
Entre os mais de cem métodos de agregação de preferências existentes, uma das sugestões apresentadas por Shepsle (2010) é o método de rodada sequencial. Supondo que seja encontrada a intransitividade, uma regra híbrida pode ser aplicada, quando várias rodadas de votação são realizadas, se na rodada $\mathcal{E}$ a alternativa com menos votos em $\mathcal{\varepsilon}-1$ for eliminada; tal processo de eliminação em novas rodadas mantém-se até que apenas uma alternativa permaneça e seja a vitoriosa.

Fazendo uso de uma estrutura semelhante à do exemplo anterior, Shepsle (2010) mostra que a intransitividade agregada (supondo que os agentes podem conhecer as preferências uns dos outros, em certos casos) oferece estímulos ao voto sofisticado (ou estratégico): esse tipo de prática gera resultados no qual o processo de agregação não representa o interesse da maioria e sim dos que possuem 0 conhecimento para gerar o resultado que mais lhe favoreça.

Ainda quanto à questão da intransitividade das preferências agregadas, Arrow (1970 [1951]) afirma, através de seu famoso Teorema da Impossibilidade, que o paradoxo de Condorcet é um problema para qualquer meio de agregação de preferências. Segundo tal teorema, não existe nenhum meio de agregação de preferências individuais de agentes racionais, em preferências grupais, que satisfaça as condições básicas de domínio universal, unanimidade, independência de alternativas irrelevantes e ausência de forças ditatoriais. ${ }^{7}$

Outro ponto a ser levantado é o fato de que, entre duas alternativas, supondo que todos os eleitores possuam boa capacidade de julgamento, a regra de maioria simples maximizará a probabilidade de o julgamento do grupo estar correto (Peyton Young, 1997). Mas, se supusermos que, pelo fato de possuírem melhor entendimento das alternativas em questão (quer porque estudaram mais a respeito das alternativas, quer porque possuem maior vivência sobre o assunto), o voto de alguns eleitores tivesse ponderação maior que a dos demais. Vejamos qual o resultado para essa suposição pelo seguinte exemplo:

\begin{tabular}{c|c|c|c}
\multicolumn{3}{c}{ Tabela 2_Maioria com diferença no nível de conhecimento } \\
\hline 7 & 7 & 6 & 1 \\
\hline$b$ & $a$ & $c$ & $a$ \\
\hline$c$ & $c$ & $b$ & $b$ \\
\hline$a$ & $b$ & $a$ & $c \ldots \ldots$
\end{tabular}

Fonte: Peyton Young, 1997.

No quadro acima, temos três alternativas possíveis, $a$, $b$ e $c$. A título de exemplo, os números 7 , nas duas primeiras colunas, o número 6 , na terceira coluna, e o número 1 , na última, representam o número de eleitores que votam nas alternativas em questão como sua primeira opção, ou seja, oito eleitores consideram $a$ como a melhor de todas, são esses os sete indivíduos da segunda coluna e o indivíduo da última coluna; e o mesmo raciocínio vale para as alternativas $b$ (7 eleitores, na primeira coluna) e $c$ (6 eleitores na terceira coluna). As alternativas estão colocadas no quadro de acordo com a ordem de preferência observada no processo, ou seja, na primeira linha estão os primeiros lugares, na segunda linha, a alternativa escolhida em segundo lugar, e, na terceira linha, a alternativa que ficou por último, no entender de cada votante.

Portanto, julgando que todos os votantes possuem conhecimento idêntico sobre o processo, temos como resultado a alternativa $a, \operatorname{com} 8$ votos, $b, \operatorname{com} 7, \mathrm{e} c, \operatorname{com} 6$ votos, isto é, são computados apenas os votos da primeira linha, como em um processo decisório no qual o ranking de resultados não é levado em conta, mas apenas o número de primeiros lugares absolutos (sem ponderação) é considerado. Entretanto, alguém pode argumentar que a alternativa $c$ é 
a melhor e, mesmo assim, recebeu o menor número de primeiros lugares. Isso pode ocorrer porque uma minoria de pessoas possui conhecimento adequado das alternativas.

A regra de Borda existe para solucionar esse problema, supondo que seja possível ponderar o voto dos agentes de acordo com seu nível de conhecimento sobre o processo eleitoral, ranqueando as alternativas com peso zero para a menos desejada, peso um para a que se encontra logo acima, e peso dois para a mais desejada, teríamos a seguinte tabela:

Tabela 3_Maioria com diferença no nível de conhecimento ponderada

\begin{tabular}{l|c|c|c|c} 
& 7 & 7 & 6 & 1 \\
\hline Peso 2 & b & a & c & a \\
\hline Peso 1 & c & c & b & b \\
\hline Peso zero & a & b & a & c \\
\hline
\end{tabular}

Fonte: Elaborado pelos autores.

Temos agora a alternativa a, com uma soma total, já ponderada, igual a 16 pontos $(7 \times 2+1 \times 2+7 \times 0+6 \times 0)$, a alternativa $b$ ficaria com 21, e a alternativa $c$, com 26 pontos. $\mathrm{O}$ ranking de Borda apresenta a alternativa c em primeiro lugar, ou seja, um resultado oposto ao da maioria simples, na qual consideramos apenas os "primeiros lugares" na votação e não consideramos pesos diferentes para eleitores diferentes. Obviamente, esse processo apresenta uma complexidade maior que uma votação por maioria simples e se torna inviável em grandes populações. Ademais, ele depende de ponderações (pesos), sempre discutíveis.

Segundo Austen-Smith e Banks (2005), a regra de Borda pode ser formalmente definida como: dado um conjunto de alternativas $\Lambda=\{s, t\}, \forall s, t \in \Gamma$, sPt se, e somente se, $\sum_{N} r_{i}(s)<\sum_{N} r_{i}(t)$, onde ri(s) é a preferência ordinal de $s$ na i-ésima escala de preferência em $\Lambda$ e $\Gamma$ é um conjunto finito de alternativas qualquer. Se considerarmos o com- portamento estratégico, dado um conjunto de indivíduos $N=\{\mathrm{X}, \mathrm{Y}, \mathrm{Z}\}$, um conjunto de alternativas $\Phi=\{a, b, c, d\}, \mathrm{Rn}$ o conjunto com todos os perfis de preferências possíveis e assumindo que as preferências são agregadas com a regra de Borda sendo o conjunto $\rho \in \mathrm{Rn}$ dado por:

$$
\begin{aligned}
& b P_{X} c P_{X} a P_{X} d \\
& b P_{Y} c P_{Y} a P_{Y} d \\
& c P_{Y} b P_{Y} a P_{Y} d
\end{aligned}
$$

Com $\rho$, a regra de Borda ordena $b P c P a P d$. Supondo que agora o indivíduo 3 estrategicamente informe a seguinte ordem de preferências: $c P_{Z}^{\prime} a P_{Z}^{\prime} d P_{Z}^{\prime} b$, no conjunto $(R 1$, $\left.R 2, R_{3}^{\prime}\right)$, a regra de Borda garante $c P^{\prime} b P^{\prime} a P^{\prime} d$. Então, com preferências verdadeiras $\rho$, devemos esperar que o indivíduo $\mathrm{Z}$ informe as preferências em $R_{3}^{\prime}$ e garanta $c$.

Outra fonte de problema inerente à regra da maioria diz respeito à incapacidade de esse processo de agregação captar a intensidade das preferências dos agentes. Segundo Buchanan e Tullock (1990 [1962]), imaginando os agentes X, Y e Z em outra situação, e um dado resultado fruto de uma eleição por maioria simples, em que o benefício gerado pela sua aprovação não é igual para todos os agentes e que: 0 agente $\mathrm{X}$ considera o resultado da votação muito produtivo, valorando sua aprovação em 10; que o agente $\mathrm{Y}$ considera o mesmo resultado moderadamente produtivo e o valora em 5; e que o agente $\mathrm{Z}$ considera o resultado pouco produtivo, valorando-o em 1; e supondo ainda que apenas \$1 será gasto no fruto do resultado do pleito, então, se todos os recursos em questão forem colocados na escolha de preferência do agente $\mathrm{X}$, sendo também este agente o único responsável pelos custos, teríamos um resultado igual a $[10 ; 0 ; 0]$. Mas não podemos nos esquecer de que a aprovação depende de uma maioria, ou seja, por exemplo, um payoff $[0 ; 5 / 2 ; 1 / 2]$ - fruto da aprovação por maioria simples e que beneficiaria exclusivamente os agentes $\mathrm{Y}$ e 
$Z$, sendo os valores correspondentes à utilidade individual de cada agente, 5 para Y e 1 para Z, ponderada pelo custo da escolha vencedora que é igual a $1 / 2$ para cada agente que a escolher - dominaria o anterior e conseguiria os votos necessários para sua aprovação, mesmo gerando uma utilidade agregada menor do que se ela toda fosse destinada ao agente $\mathrm{X}$, como na hipótese anterior. A aprovação depende de maioria simples, e o orçamento é igual a $\$ 1$ e o custo de cada escolha alvo de votação em princípio é dividido entre os que receberão o benefício, e a parte excluída não é responsabilizada pelo ônus de um resultado que não lhe traga benefício. Mesmo que a utilidade gerada nos três indivíduos seja diferente, o custo é dividido igualmente entre as duas partes pagantes, ou seja, com $\$ 1 / 2$ para cada uma. Lembrando que o benefício gerado aos agentes, caso a preferência de cada um seja aprovada, sem os custos dessas, é dado por:

$\begin{array}{lll}\mathrm{X} & \mathrm{Y} & \mathrm{Z} \\ {[10 ;} & 5 ; & 1\end{array}$

Portanto, ponderando o custo de $\$ 1 / 2$ para cada agente beneficiado pela aprovação de sua escolha, com a utilidade gerada a ele, teremos o seguinte resultado das alianças formadas entre XY, XZ e YZ, respectivamente:

$$
\begin{aligned}
& \text { X Y Z } \\
& \text { [5; 5/2; } 0] \\
& \text { [5; } 0 ; 1 / 2] \\
& {[0 ; \quad 5 / 2 ; 1 / 2]^{8}}
\end{aligned}
$$

Notamos que tais resultados geram um payoff"menos produtivo" que [10; 0; 0], e esse é um problema gerado pela regra da maioria, ou seja, a intensidade das preferências não foi captada. Antes de falarmos de troca de votos, suponhamos que compensações unilaterais possam ser usadas, isto é, que os agentes possam fazer trocas em dinheiro para obter o resultado almejado. Como o orçamento disponível para o projeto fruto do processo eleitoral é \$1, imaginando que a preferência de apenas um cidadão seja aprovada, teríamos

\begin{tabular}{|c|c|}
\hline $\mathrm{X}$ & $\mathrm{Y}$ \\
\hline$[5 ;$ & 5 \\
\hline$[5 ;$ & 0 \\
\hline ; & 5 \\
\hline
\end{tabular}
um "resultado financeiro" igual a \$ 10 para $\mathrm{X}, \$ 5$ para Y e $\$ 1$ para Z. Se assumirmos que a troca existe o resultado passa a ser:

$\mathrm{Na} 1^{\mathrm{a}}$ combinação, o indivíduo $\mathrm{X}$ tem todo o orçamento a seu dispor, mas ele precisa pagar ao agente $Y$ metade desse valor para obter dele suporte; na combinação 2, os agentes $\mathrm{Y}$ e $\mathrm{Z}$ apenas mudam de lugar. A terceira combinação indica que o indivíduo $X$ consegue aprovar sua escolha, mas $\mathrm{Y}$ e $\mathrm{Z}$ se juntam para extrair de $\mathrm{X}$ o excedente que ele conseguiu, no caso $\$ 10$.

Supondo que todos tenham que arcar com o custo da preferência aprovada, e não somente com os beneficiários dessa, como consideramos até agora, o que equivale a dizer que a escolha (preferência) aprovada seria financiada por um imposto cobrado igualmente sobre toda a sociedade (voltemos ao caso de uma escolha que gere um benefício de magnitude 1 ao todo), e que o imposto cobrado sobre toda a sociedade possui este mesmo valor $(\$ 1)$. Como dito, veremos adiante que coalizões de dois indivíduos dominam coalizões de três indivíduos; isso nos deixa à vontade para supormos que os seguintes resultados são possíveis: 
$[1 / 2 ; 1 / 2 ; 0],[1 / 2 ; 0 ; 1 / 2]$ e $[0 ; 1 / 2 ; 1 / 2]$. Todavia, não pode ser ignorado o custo da escolha fruto da eleição por maioria, quando é dividido por toda a população em questão. Pois, como o imposto geral é igual a $\$ 1$, e no exemplo a população é composta de três agentes, cada um contribuindo igualmente com $\$ 1 / 3$, isso nos mostra que uma pessoa entre as três sempre fica em pior situação após o resultado eleitoral, no caso, o agente que fica com o resultado zero nos payoffs apresentados anteriormente, pois paga um imposto de $\$ 1 / 3$ e não recebe nada em troca, enquanto os outros dois agentes pagam o mesmo imposto, mas recebem um benefício igual a $\$ 1 / 2$.

Portanto, vemos que a regra da maioria gera, para a parte perdedora, um resultado negativo. A princípio, podemos supor que não é racional uma pessoa participar de um jogo que lhe traga um benefício negativo, mas as pessoas não podem escolher se pagam impostos ou não, trata-se de uma atividade compulsória. Assim, inevitavelmente, nesses casos, a regra da maioria gera perda na parte que fica de fora da coalizão formada para obter o resultado desejado.

Notamos, então, que a regra da maioria pode ser uma opção interessante na impossibilidade do consenso, por apresentar custos bem menores que este último. Contudo, não podem ser ignorados os problemas que essa regra gera, como a questão das externalidades negativas, a capacidade de alteração de resultados via manipulação de agenda, quando o paradoxo do voto é encontrado, e a falha na capacidade de captar a intensidade das preferências dos agentes, em um processo decisório. Este último é o principal problema gerado por tal processo de decisão.

Para a heterogeneidade na intensidade das preferências dos agentes, a solução que abordaremos aqui e que tenta resolver certas questões referentes a processos de agregação de preferências é o logrolling. A troca de votos existe para permitir que uma minoria muito desejosa de dado projeto não seja tiranizada por uma maioria aparentemente apática em relação a ele. O logrolling aparece quando a intensidade na preferência dos agentes é diferente e não o seu nível de conhecimento sobre as alternativas.

\section{3_0 logrolling}

Anteriormente abordamos os problemas gerados pela regra da maioria e suas possíveis soluções. Uma das tentativas para buscarmos um resultado aparentemente mais justo nos processos de agregação de preferências ocorreria com a troca de votos, em que cada agente é capaz de mensurar a utilidade gerada para si, por dado projeto, e negociar sua preferência na atual pauta e em pautas futuras. Vejamos o seguinte caso:

Tabela 4_Exemplo básico de logrolling

\begin{tabular}{c|c|c} 
Votantes & Proposta $a$ & Proposta $b$ \\
\hline$X$ & 7 & -3 \\
\hline$Y$ & -3 & -3 \\
\hline$Z$ & -3 & 7
\end{tabular}

Fonte: Elaborado pelos autores.

Na Tabela 4, observamos que existem três votantes (X, Y e Z) e duas propostas ( $a$ e $b$ ). Os números 7 e - 3 representam a utilidade gerada ao indivíduo, caso a proposta em questão seja aprovada, isto é,é o benefício esperado pelo agente no caso da aprovação da proposta. Se uma regra de maioria simples for utilizada, nenhuma proposta será aprovada, já que, no caso do projeto a, os agentes $\mathrm{Y}$ e $\mathrm{Z}$ votam contra, e, na votação para a proposta $b$, são os indivíduos $\mathrm{X}$ e $\mathrm{Y}$ que se opõem, totalizando assim dois votos contra um; em ambas, a utilidade total será, então, igual a zero. Note-se, 
porém, que, se os indivíduos $\mathrm{X}$ e $\mathrm{Z}$ resolverem trocar votos com $\mathrm{Z}$, votando a favor de a desde que $\mathrm{X}$ vote a favor de $\mathrm{b}$, ambas serão aceitas, e a utilidade total será igual a 2 - com a aprovação de a, X ganha 7, já Y e Z perdem juntos 6, totalizando uma soma de utilidade positiva igual a 1; graças ao logrolling, b também é aprovada, gerando uma perda de utilidade igual a -3 para os agentes $\mathrm{X}$ e $\mathrm{Y}$, -6 no total, e um ganho de 7 para o agente Z. Somando-se o ganho agregado de utilidade de a com b, chegamos ao valor 2. Neste caso, consequentemente, o logrolling gerou um benefício para a sociedade de forma geral. Agora, se em vez de utilizarmos -3 na tabela considerarmos -4 , a troca gera uma utilidade agregada de $-2 .{ }^{9}$

O exemplo anterior é um jogo de forma extensiva, no qual, por simplificação, o agente $Y$ não participa, dado que se opõe às duas alternativas, e, tendo início o jogo com $\mathrm{X}$ votando a favor de a, teríamos:

\section{Gráfico 1_ Jogo extensivo entre Agentes Z e X}

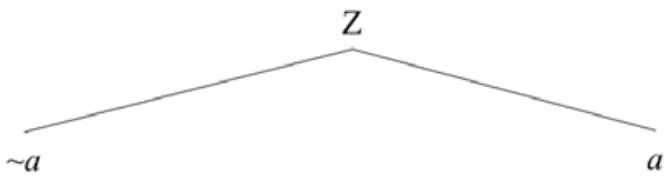

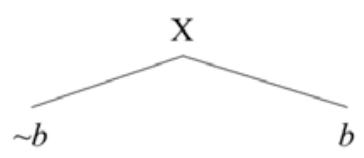

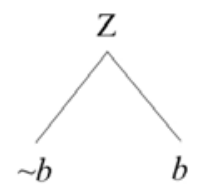

$(0,0)$
$(0,0)$

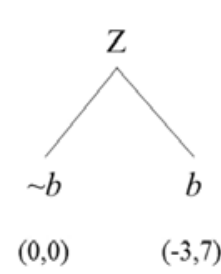

$(-3,7)$
Fonte: Elaborado pelos autores. quanto a regra da maioria considera as preferências dos indivíduos de maneira apenas ordinal, o logrolling permite que a intensidade dessas preferências seja captada. De acordo com Mueller (2009), a troca de apoio a projetos e votações existe porque as preferências a favor e contra determinadas questões não são iguais para os vários agentes. Assim, a troca evita que uma minoria muito desejosa de um dado projeto seja tiranizada por uma maioria aparentemente indiferente ao mesmo projeto, maioria a qual a minoria pode tentar convencer, pelo mecanismo de troca de apoio. Do anterior, concluímos que, para que a troca seja benéfica, é necessário que o aumento da utilidade da minoria beneficiada com ele seja maior que a perda de utilidade provocada na maioria. No primeiro exemplo anterior, o ganho da minoria era 7 , ao passo que a perda da maioria era igual a 6 , gerando, assim, uma troca benéfica.
Com base nisso, podemos perceber que o logrolling 
Carruba e Volden (2000) afirmam que o logrolling é facilitado quando existem poucos políticos, os projetos trazem mais benefícios que custos, o futuro tem grande valor, a chance de reeleição é alta, a coalizão é fácil de ser formada e as regras de votação são menos inclusivas. Segundo Bernholz (1973), a situação de logrolling só é possível se as preferências sociais forem intransitivas. Stratmann (1997) explica que os custos de uma preferência aprovada devem, em muitos casos, ser pagos por todos, e não apenas pelos seus beneficiários, gerando nestes últimos a sensação de que a escolha saiu barato. Isso implica um aumento da oferta dessas escolhas, gerando uma transferência dos recursos da minoria vencida para a maioria (coalizão) vencedora.

Outra abordagem para demonstrar os benefícios e os malefícios do logrolling, já que o exemplo de preferências agregadas parece um tanto abstrato - pela dificuldade de obtermos tal medida, além de termos de supor que os agentes sempre relatam suas preferências com veracidade -, diz respeito à estabilidade ou à instabilidade das coalizões. De acordo com Stratmann (1997), se as coalizões forem instáveis politicamente, os benefícios da troca de votos não aparecem pelo seguinte motivo: se no exemplo anterior, o indivíduo X, após receber o apoio de Z, não retribuí-lo, apenas uma das propostas seria aceita, diminuindo em um primeiro lance a utilidade agregada gerada pela votação; ao repetirmos esse esquema de traição (encarada como a instabilidade das coalizões), facilmente enxergamos que, no limite, nenhuma proposta seria aceita, fazendo com que o processo político deixasse de agregar valor à sociedade. O raciocínio anterior de outra maneira, quando fazemos uso de teoria dos jogos: devemos, então, nos ater a conceitos de jogos repetidos, pois, supondo que, na Tabela 4, além das propostas $a$ e $b$, existam outras duas mais, $c$ e $d$, que geram respectivamente $7 \mathrm{e}-3$ de utilidade ao agente $X,-3 \mathrm{e}$ -3 ao agente $Y$ e -3 e 7 ao agente $Z$, tal jogo repetido entre $X$ e Z gera 128 payoffs com as combinações de votação entre os agentes, o que inviabiliza uma análise visual baseada em indução da árvore de decisões.

De acordo com Myerson (1991), jogos repetidos possuem um horizonte de tempo infinito ${ }^{10}$ e ainda, como cada movimento não é necessariamente o último, neles um jogador deve se preocupar com o efeito que sua decisão atual pode ter nas decisões dos outros jogadores no futuro. O comportamento generoso, ou cooperativo, em jogos repetidos, advém da alta probabilidade que os agentes terão de se encontrar futuramente em um novo jogo. Então, a esperança de criar um comportamento generoso ou cooperativo no outro participante cria no responsável pela decisão atual um comportamento igualmente generoso. Formalizando:

Seja $\Theta$ o conjunto dos possíveis estados de natureza, $\theta_{k}$ o estado de natureza na rodada $k, S_{i}$ o conjunto de sinais que o jogador $i$ pode receber em cada rodada, sendo que cada nova informação do jogador i sobre o estado de natureza é resumida por um sinal $s \in S_{i}$ que ele recebe no começo da rodada. Como uma função dos sinais recebidos na rodada atual e em todas as anteriores, cada jogador deve escolher $D_{i}$, sendo $D_{i}$ o conjunto de movimentos que o jogador i pode realizar e $d_{k}$ os movimentos possíveis do jogador em questão, na rodada $k$, $\delta$ um fator de desconto aplicado à sequência de payoffs do i-ésimo jogador na k-ésima rodada $\left(\mathrm{w}_{i}(\mathrm{k})\right)$, de modo que a média descontada pelo fator $\delta$ seja: $(1-\delta) \sum_{k=1}^{\infty} \delta^{k-1 \times} w_{i}(k)$, com $0 \leq \delta<1$, o que é interpretado como uma medida de paciência de longo prazo do jogador; quando apresenta valores próximos a zero, os agentes concentram seu foco no presente, e com valores próximos a 1, possuem maior preocupação com os resultados futuros. Seja também $\tau$ uma estratégia estacionária para o jogador $\mathrm{i}, \operatorname{com} \tau_{i}: \Theta \rightarrow \Delta(D i), v_{i}$ é o resultado descontado por $\delta$ para o jogador i, em jogos repetidos, se 
os jogadores pretendem sempre usar $\tau$ e se, no início da rodada 1,0 estado de natureza for $\theta, \operatorname{com} v_{i}=\left(v_{i}(\theta)\right) \theta \in \Theta$. Se o jogador pretende implantar $\tau$ em todas as rodadas, com exceção da rodada 1 , na qual ele pretende jogar $d_{i}$, e se o estado de natureza em 1 for $\theta$, então o resultado descontado por $\delta$, para o jogador i $\left(\mu_{i}\right)$ é:

$$
\begin{aligned}
\mu_{i}\left(\tau, d_{i}, v_{i}, \theta, \delta\right)=\sum_{d_{-i} \in D_{-i}}\left(\prod_{j \in N_{-i}} \tau_{j}\left(d_{j} \mid \theta\right)\right) \\
\quad\left((1-\delta) u_{i}(d, \theta)+\delta \sum_{\theta_{2}} \sum_{s \epsilon} p\left(s, \theta_{2} \mid d, \theta\right) v_{i}\left(\theta_{2}\right)\right) .
\end{aligned}
$$

Dadas as definições anteriores, é possível provar (Myerson, 1991) que, em um jogo repetitivo, com informações completas e resultados limitados, e dado um perfil de estratégias estacionárias como $\tau$, se existe um vetor limitado $v=\left(v_{i}(\theta)\right)$ $\theta \in \Theta, i \in N$ de tal forma que as condições abaixo sejam satisfeitas para cada jogador i:

$v_{i}(\theta)=\sum_{d_{i} \in D_{i}} \tau_{i}\left(d_{i} \mid \theta\right) \mu_{i}\left(\tau, d_{i}, v_{i}, \theta, \delta\right), \forall \theta \in \Theta$,

e também; $v_{i}(\theta)={ }_{d_{i} \in D_{i}} \mu_{i}\left(\tau, d_{i}, v_{i}, \theta, \delta\right), \forall \theta \in \Theta$ então $\tau$ é um equilíbrio do jogo repetitivo sob o critério do resultado descontado por $\delta$. Nesse equilíbrio, $v_{i}(\theta)$ é o resultado descontado por $\delta$ para o i-ésimo jogador, no jogo repetitivo, quando o estado de natureza inicial é $\theta$, considerando $\Theta$ $=\mathrm{f}\left(S_{i}\right)$. Ou seja, sinais encarados como traição ou não cooperação influenciam o resultado futuro, neste caso, diminuindo $\left(w_{i}(k)\right)$.

É a partir deste ponto que se inicia o debate sobre os benefícios e os malefícios da troca de votos: os que acreditam na instabilidade atentam para os malefícios da troca de votos, enquanto que os defensores da estabilidade afirmam que o logrolling gera benefícios, se analisados de maneira agregada. ${ }^{11}$

Buchanan e Tullock (1990 [1962]) afirmam que a troca de votos só é difícil em certos processos decisórios, como, por exemplo, os referendos, uma vez que nunca se sabe quando será o próximo evento em que a troca poderá ser concretizada. Outra fonte de problemas ao logrolling em referendos é o tamanho da população; nesse cenário de referendo, por exemplo, cada agente representa uma parte ínfima do universo de votantes.

\section{4_A estabilidade das trocas}

Tomando como ponto central a questão da estabilidade das coalizões, para os que utilizam esse argumento teórico, a fim de defender a troca de votos como benéfica, assim como a troca de mercadorias o é no mercado privado de bens e serviços, apresentaremos posições sobre a estabilidade das coalizões formadas para a prática do logrolling. ${ }^{12} \mathrm{Um}$ estudo sobre a estabilidade das coalizões merece atenção, visto que oferece o arcabouço teórico utilizado para defesa da prática do logrolling, já que é vista pela maioria da população como deletéria.

Como defendido anteriormente, coalizões instáveis levam a um cenário futuro no qual nenhuma proposta é aprovada nos pleitos, gerando um malefício para a sociedade, que não terá nenhuma de suas demandas atendidas. Não obstante, veremos por que essa traição geralmente não ocorre. No exemplo da Tabela 4, podemos notar que, mesmo sendo muito vantajoso para o agente A romper a coalizão, e existem autores que se apoiam nessa ideia, outros autores mostram que o agente não a romperá.

Tullock (1981) ${ }^{13}$ faz uma abordagem a respeito da estabilidade das coalizões formadas para a prática do logrolling explícito - em que as trocas são feitas em proposta individuais entre os votantes - e também para a prática do logrolling implícito - nas quais as trocas são realizadas antes de a proposta ir a pleito, sendo votadas e aprovadas posteriormente, como um único pacote, uma vez que tudo já fora combinado antes. Para ele, no logrolling explícito, todos participam das trocas, e todas as propostas são aceitas, pois, se alguém esti- 
ver de fora, esse pode obter resultado mais vantajoso traindo a atual coalizão e formando uma nova. Por exemplo, imagine-se que a regra de maioria simples seja a utilizada, e o universo de votantes seja composto por cinco agentes, a saber, V, W, X, Y e Z. Logo, são necessários três votos para a aprovação de qualquer proposta. $\mathrm{O}$ agente $\mathrm{V}$ fecha um acordo com W e com X para a aprovação da proposta de seu interesse; isso faz com que $\mathrm{W}$ tenha dois votos para a posterior aprovação da sua proposta - o próprio voto e o voto de $\mathrm{V}$, considerando obviamente que as alianças não sejam rompidas no futuro. $\mathrm{O}$ indivíduo $\mathrm{W}$ precisará de mais um voto, digamos, ele poderá conseguir o apoio de $\mathrm{Y}$, em troca de uma compensação futura. Suponhamos que $\mathrm{X}$ faça a mesma coisa, mas com o indivíduo Z. Assim, todos participam de alianças, e todas as propostas são aprovadas.

Para Tullock (1981), o problema surge no logrolling implícito. Utilizando um exemplo já apresentado na seção 1 deste artigo, de acordo com Buchanan e Tullock (1990 [1962]), nada garante que o resultado em uma votação por maioria simples beneficiará todos os envolvidos. Imagine uma proposta que gere um benefício de magnitude 1, existindo três agentes que participam de um processo decisório, os agentes X, Y e Z. Nenhuma coalizão que ocasiona um resultado agregado igual a zero pode ser formada, mas coalizões de dois indivíduos podem ser formadas, originando um resultado de $1 / 2$ para cada participante e zero para o agente que ficou de fora da aliança, além de, alternativamente, uma coalizão de três agentes (consenso), resultando em um benefício de $1 / 3$ para cada agente. A solução para uma coalizão de dois indivíduos é dada por:

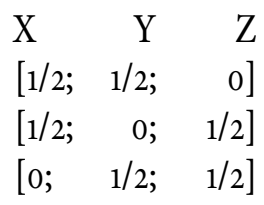

$O$ resultado da coalizão entre os agentes $\mathrm{Y}$ e $\mathrm{Z}$ é: [0; 1/2; $1 / 2]$. Então, $X$ pode propor uma redistribuição no resultado para $[1 / 4 ; 3 / 4 ; 0]$, a fim de que o agente $Y$ traia o agente $\mathrm{Z}$ e faça uma nova aliança, tornando os indivíduos $\mathrm{X}$ e $\mathrm{Y}$ em uma situação melhor do que no início do processo (representado pelo payoff $[0 ; 1 / 2 ; 1 / 2])$. Todavia, o resultado dessa nova aliança - $[1 / 4 ; 3 / 4 ; 0]$ - é dominado por outro, que pertence ao quadro de soluções para coalizões de dois indivíduos, dado por $[1 / 2 ; 0 ; 1 / 2]$, formado pelos agentes $\mathrm{X}$ e Z, ou seja, após o agente $\mathrm{Y}$ trair o agente $\mathrm{Z}$ e se unir ao agente $\mathrm{X}$, este último trai o agente $\mathrm{Y}$ e se une ao agente $\mathrm{Z}$. Vale dizer, qualquer resultado fruto de uma aliança entre dois indivíduos domina o resultado $[1 / 3 ; 1 / 3 ; 1 / 3]$. Portanto, o resultado fruto de uma regra de maioria, a princípio, não é estável. Notamos que o esquema acima, em uma primeira observação, apresenta um ciclo sem fim, ou seja, sempre o indivíduo de fora da coalizão fará uma oferta de traição para um dos membros da aliança. ${ }^{14}$

No entanto, se olharmos para o agente $\mathrm{Y}$, ao sair da coalizão que mantém com $Z$ e entrar em um conluio com $X$, este passará a ter um payoff bem maior do que possuía antes - passando de $1 / 2$ para $3 / 4-$, o que a princípio parece ser bem vantajoso para ele. Entretanto, neste novo resultado, Z, $\mathrm{o}$ agente traído, poderia propor a $\mathrm{X}$ que rompa seu contato com Y e faça um novo com ele, ganhando, por exemplo, $1 / 2$ -, o que faria X passar de 1/4 para 1/2 - é esta segunda traição, quando $X$ abandona $Y$ e se alia a $Z$, que gera estabilidade ao sistema. Se, na primeira oferta de $\mathrm{X}$ para que $\mathrm{Y}$ traia $\mathrm{Z}, \mathrm{Y}$, o agente alvo da proposta, tem em mente que formará uma nova coalizão em que será o maior beneficiário - $[1 / 4 ; 3 / 4$; o] - e que essa nova coalizão poderá ser desfeita porque $\mathrm{X}$ consegue um resultado melhor se aliando posteriormente a $Z$ - $[1 / 2 ; 0 ; 1 / 2]$ - a primeira proposta de traição feita por $\mathrm{X}$ a $\mathrm{Y}$ nunca será aceita, pois $\mathrm{Y}$ sabe que poderia obter um resultado bem maior que seu aliado (no caso $\mathrm{X}$ ), mas que 
este último, se quiser, poderá conseguir um payoff mais vantajoso posteriormente.

Isso nos leva ao fato de que uma coalizão de maioria simples, em que os resultados de todos os membros são iguais, é estável. Uma coalizão em que todos possuem o mesmo payoff é chamada de igualitária, enquanto uma na qual alguns ganham mais que outros é aristocrática. De acordo com Tullock (1981), os membros de uma coalizão igualitária nunca rumarão para uma aristocrática - pelo exposto acima -, ao passo que os membros menos favorecidos de uma aristocrática sempre procurarão uma igualitária. Dessa maneira, quando uma coalizão igualitária é formada, o sistema entra em equilíbrio, e não existem incentivos para comportamentos traidores. $O$ raciocínio anterior pode ser apresentado de uma maneira mais formal utilizando os conceitos de jogos cooperativos com resultados transferíveis, como exposto por Osborne e Rubinstein (1994): dado um conjunto com $N$ agentes, para cada coalizão $G$, o número $r(G)$ é o resultado fruto da divisão entre os membros de $G$; o conceito de core implica que um resultado é estável se nenhuma nova coalizão com resultados melhores para todos os membros pode ser formada. Sendo que, para qualquer conjunto de números reais $\left(x_{i}\right)$ $i \in N$, e qualquer coalizão $G$, existe $x(G)=\sum_{d_{i} \in D_{i}} x_{i}$. Se $x(G)$ $=r(G)$, o vetor $\left(x_{i}\right) i \in G$ é um vetor de resultado possível ou factível. O core de um jogo cooperativo $(N, r)$ é o conjunto de resultados possíveis $\left(x_{i}\right) i \in N$ para os quais não existe uma coalizão $G$ e um vetor $G$ de resultado possível $\left(y_{i}\right) i \in G$, para os quais $y_{i}>x_{i}$, para todo $i \in G^{15}$.

Sendo $C$ o conjunto de todas as coalizões, para qualquer coalizão $G$ dada por $\mathbf{R}^{\mathrm{G}}, G$ o espaço Euclidiano no qual as dimensões são indexadas por membros de $G$ e dados por $1_{G} \in \mathbf{R}^{\mathrm{N}}$, o vetor característico $G$ é dado por: $\left(1_{G}\right) i=\{1$ se $i \in G$; ou zero em casos contrários\}. Uma compilação $\left(\alpha_{G}\right)_{G \in C}$ de números entre [0,1] é uma compilação balanceada se $\sum_{G \in C} \alpha_{G} 1_{G}=1_{N}$.
Um jogo $(N, r)$ é balanceado se $\sum_{G \in C} \alpha_{G} r(G) \leq r(N)$. Então, o teorema de Bondareva-Shapley atesta ${ }^{16}$ que um jogo cooperativo com resultados transferíveis possui um core não vazio se, e somente se, ele for balanceado. Assim sendo, do exemplo anterior, observa-se que o core foi definido por Tullock como a coalizão igualitária.

Restringindo um pouco a análise para o comportamento parlamentar, Koford (1982) igualmente acredita na estabilidade das coalizões, mesmo utilizando uma abordagem diferente da de Tullock. Por sua vez, Koford (1982) foca sua atenção no comportamento dos líderes partidários, para mostrar que a rede de contatos legislativos não é tão complexa e desorganizada quanto pode parecer, em uma primeira análise. Dentro dessa perspectiva, as trocas são feitas em torno de um agente comum, o líder partidário. Assim, os legisladores trocam votos apenas com seu líder, apoiando o partido e seu "legislador chefe", em troca do apoio do líder e de sua maioria para a aprovação futura de seus projetos pessoais. Então, para analisar o comportamento das trocas em Koford, devemos analisar o comportamento do líder.

De acordo com o autor, o líder possui três restrições para definir qual projeto passa e qual é rejeitado; devemos ter em mente que o líder deve ter total domínio sobre os votos de seus comandados, isto é, sua indicação sempre deve ser acatada pela sua bancada. Uma primeira restrição é que o líder deve ser sincero, em suas promessas, vale dizer, se afirma que vai fazer de tudo para aprovar determinado projeto, deve fazê-lo, e, se disser o contrário, deve agir da mesma forma. Essa restrição se faz presente, uma vez que o líder almeja sua reeleição para o cargo de comandante da bancada, no próximo período; então, se ele não cumprir sua promessa, seus colegas parlamentares - que são quem elegem o líder partidário - escolherão outro agente para exercer a função, em um futuro pleito. 
A segunda restrição surge quando existem apenas dois partidos na arena, caso típico do legislativo norte-americano. Aqui os líderes se encontram em uma situação muito próxima do duopólio, ou seja, um líder não pode ser menos esforçado em suas atividades do que o outro, pois os parlamentares procuram o líder em busca de uma maioria para aprovação de seus projetos pessoais. Portanto, se o líder de seu partido não lhe oferecer esse resultado, ele pode procurar um que o faça, o que permitiria que os líderes, em um caso de bipartidarismo, entrassem em uma disputa semelhante à observada em um duopólio.

A terceira e última restrição aparece em futuros concorrentes que hoje se apresentam como aliados: são os sublíderes, no caso de uma bancada partidária muito grande, visto que existem agentes encarregados de determinados setores dentro dela. Suponha, por exemplo, que um partido muito grande tenha representantes ligados aos esportes, à indústria e à agricultura, e um único líder seja encarregado de nomear um sublíder para cada um desses três. $\mathrm{O}$ líder deve-se manter atento também para que um de seus subordinados não tome o seu lugar, no futuro. Se souber administrar a atuação de todos os seus subordinados - os parlamentares comuns e os sublíderes - o líder possuirá características de um monopolista dentro de seu partido, vendendo aprovações de projetos, dado que controla uma maioria. Portanto, para esse monopólio do líder, ele deve estar atento a mais três questões, a fim de tomar suas decisões: as suas preferências, as preferências de sua bancada e as preferências da bancada que será eleita nas próximas eleições, pois ele procura se antecipar e agradar os futuros legisladores, já pleiteando apoio para suas demandas futuras. Assim, se o líder respeitar tais restrições, a análise do logrolling entre ele e sua bancada pode ser feita como na teoria microeconômica neoclássica, não existindo instabilidade e podendo, ademais, ser facilmente modelada.
Voltando para casos mais genéricos, Coleman (1967) faz uma abordagem semelhante à de Tullock (1981), focando, porém, na questão da credibilidade dos agentes. Suponha a seguinte matriz de payoffs:

Tabela 5_A estabilidade das trocas e o payoff dos agentes

\begin{tabular}{|c|c|c|}
\hline Votante & Proposta a & Proposta b \\
\hline$x$ & -1 & -1 \\
\hline Y & $+1,9$ & $-0,1$ \\
\hline Z & $-0,1$ & $+1,9$ \\
\hline
\end{tabular}

Fonte: Coleman, 1967.

Pela regra de maioria, nenhuma proposta passa, pois são necessários dois votos para aprovação, e, como podemos ver individualmente, nem a proposta $a$ nem a proposta $b$ geram benefício positivo para os votantes $\mathrm{X}, \mathrm{Y}$ e Z, simultaneamente. Mas suponha que as seguintes trocas, entre os agentes $Y$ e Z, possam ser feitas, a partir da tabela anterior. Teríamos, então, o seguinte resultado, fruto dessa cooperação entre os agentes citados:

Tabela 6_A estabilidade das trocas e o payoff dos agentes em diferentes cenários

\begin{tabular}{|c|c|c|c|c|}
\hline Votante & ++ & +- & -+ & -- \\
\hline$x$ & -2 & -1 & -1 & 0 \\
\hline Y & +1.8 & +1.9 & -0.1 & 0 \\
\hline Z & +1.8 & -0.1 & +1.9 & 0 \\
\hline
\end{tabular}

Fonte: Elaborado pelos autores.

Pela Tabela 6, os votantes continuam os mesmos (X, Y e Z),++ significa que tanto a proposta $a$ como a proposta $b$ foram aceitas, + - apresenta uma situação na qual apenas a primeira proposta consegue vitória. No caso do 
resultado - +, apenas a segunda é acatada pelos votantes em questão e, por fim, - - é o cenário no qual ambas as propostas são rejeitadas. Os valores numéricos representam o resultado para o agente em questão, fruto da aprovação de determinada(s) proposta (s). Por exemplo, como o agente $\mathrm{X}$ tem uma utilidade negativa de magnitude 1 , na aprovação da proposta $a$, assim como na aprovação da proposta $b$, no cenário + + ele acabaria com um resultado de magnitude negativa igual a 2.0 mesmo vale para os outros agentes e suas respectivas utilidades.

O resultado + + é o que apresenta estabilidade. Supondo novamente um cenário no qual possa existir um comportamento traidor, a troca inicial entre $\mathrm{Y}$ e $\mathrm{Z}$ para aprovação de ambas as propostas gera um benefício igual a +1.8 para cada um. Para um argumento a favor da instabilidade dessa coalizão, pode-se imaginar que $X$ poderia oferecer um novo acordo, de modo que $Y$ traia $Z$, migrando o resultado dessa forma para +- em que tanto $X$ quanto Y estariam melhores do que no cenário ++ (passando o primeiro de um resultado -2 para -1, e o segundo passando de +1.8 para 1.9). Note-se agora que uma nova traição pode aparecer, na qual o agente $\mathrm{Z}$ propõe ao agente $\mathrm{X}$ que traia seu parceiro Y migrando o resultado novamente, mas agora para o cenário - - (onde $\mathrm{X}$ passaria de -1 para zero e $\mathrm{Z}$ passaria de $-0,1$ para zero). Note-se também que a posição do agente $Y$ para se manter no acordo inicial $(++)$ tende a ser mais firme que a posição de $\mathrm{X}$ para se manter no último acordo (- -), para a qual poderia ocorrer um novo acordo entre $\mathrm{Y}$ e Z, fazendo o sistema retornar para a posição $(++)$.

Desta forma, o resultado ++ tende a ser estável, já que $\mathrm{X}$ tem mais a ganhar, em termos absolutos e proporcionais, quebrando + -, do que Y quebrando + +. Assim, a estabilidade é definida em termos das utilidades esperadas dos votantes, fruto das probabilidades das quebras dos acordos. Ademais, para Coleman, se uma pessoa quebrar um acordo hoje, ela poderá nunca mais conseguir entrar numa coalizão futura ou incorrerá em alto custo para readquirir uma reputação; desta forma, a credibilidade é um ponto-chave no raciocínio esboçado acima.

Outro autor que defende a estabilidade é Bernholz (1978), o qual apresenta um modelo matemático para demonstrar que, dentro de grupos de interesses bem fundamentados, com longa existência, as coalizões formadas com o intuito da prática do logrolling explícito são estáveis ao longo do tempo. Isso se deve a fatores de reputação adquirida ao longo do período e que possuem alto custo para serem readquiridas em caso de perda.

\section{5_Considerações finais}

No presente artigo, pudemos observar que o sistema de consenso é capaz de causar uma externalidade negativa de magnitude zero à população. Pela sua óbvia dificuldade de implementação e administração, a regra do consenso mostra-se inviável. Como alternativa, buscamos observar a regra da maioria, sua implementação e uso. Entretanto, problemas gerados por tal regra não podem ser ignorados, como a questão das externalidades negativas; a capacidade de alteração de resultados via manipulação de agenda, quando o paradoxo do voto é encontrado; e a falha na capacidade de captar a intensidade das preferências dos agentes. Como solução aparente para o último dos três problemas apresentados, surge, então, a troca de votos, para que a intensidade das preferências dos agentes seja captada, e o mínimo de externalidades seja gerado.

Analisando o logrolling, apresentamos argumentos em favor da estabilidade como fator gerador de benefícios oriundos da troca de votos. Apresentamos também teorias que pregam a estabilidade das coalizões e constatamos, dentro das teorias expostas, que os indivíduos não possuem incentivos 
para quebrar uma aliança, porque, fazendo isso, eles iriam para uma situação futura mais vulnerável do que a presente - por exemplo, saindo de uma coalizão igualitária e partindo para uma aristocrática, $o$ agente saberia que, no futuro, seria traído e acabaria em uma situação na qual não participaria de nenhuma aliança, obteria um payoffigual a zero e ainda veria os seus impostos financiarem os projetos aprovados pela maioria, o que não lhe traria benefício algum. A credibilidade foi apresentada também como um fator aliado ao anterior, que influencia na manutenção das alianças.

Espera-se que a exposição aqui realizada a respeito das teorias sobre a regra da maioria, suas deficiências e as soluções possíveis para elas sejam útil para o debate acadêmico ao oferecer um compilado teórico sobre o tema para futuros estudos.

\section{Notas}

${ }^{1}$ Para uma análise do sistema proporcional (atualmente praticado no Brasil, para pleitos legislativos) e do comportamento observado do agente público fruto desse sistema, o leitor poderá consultar, entre outros: Limongi e Figueiredo (1999; 2002),

Pereira e Mueller $(2002 ; 2003)$ e Carvalho (2006).

${ }^{2}$ Aliado a esses efeitos, Schofield (1997) defende ainda o princípio da credibilidade, como mecanismo de exclusão de partidos. Segundo tal princípio, se as agremiações políticas fazem promessas ao eleitorado, e os eleitores sabem que essas têm alto custo aos partidos, para que aquelas se mantenham críveis, elas têm de barganha e o aparecimento de soluções mais (ou mesmo perfeitamente) inclusivas (Buchanan; Tullock, 1990 [1962]).

${ }^{5}$ Definindo uma regra de agregação $f$ como transitiva quando para todo $\rho \in R \mathrm{n}, f(\rho)$ é transitiva; $f$ é quase transitiva se para todo $\rho \in R \mathrm{n}, f(\rho)$ é quase transitiva; e acíclica se para todo $\rho \in R \mathrm{n}, f(\rho)$ é acíclica (AustenSmith e Banks, 2000). Com $r$ o conjunto capaz de descrever a preferência de todos os indivíduos e $R^{\mathrm{n}}$ o conjunto com todos os perfis de preferências possíveis.

${ }^{6}$ A afirmação é provada por McKelvey (1976), mostrando que, se as alternativas dos participantes do processo de escolha não estiverem alinhadas, não haverá um ponto vencedor dominante em votação por regra de maioria (vencedor Condorcet). Neste caso, o poder de agenda torna-se a regra na determinação da alternativa a ser escolhida. Para McKelvey, a hipótese de alinhamento das alternativas é restritiva e possui baixa probabilidade de ocorrência.

${ }^{7}$ O Teorema do Pico Único de Black (1998 [1958]) mostra que a regra de maioria pode apresentar bons resultados de agregação de preferências, desde que o pressuposto da utilização de "preferências de pico único" seja utilizado.

${ }^{8} \mathrm{Na}$ próxima seção, apresentaremos argumentos que nos levam a crer que um resultado fruto de uma aliança entre dois membros da população domina um resultado que favoreça os três membros desse mesmo processo.

${ }^{9}$ Para o exemplo em questão, não consideramos a possibilidade do voto sofisticado.

${ }^{10}$ Jogos finitos também existem, como propõem Osborne e Rubinstein (1994). Entretanto, eles definem um jogo infinito como aquele em que, após uma rodada, os agentes acreditam que o jogo continuará por um período adicional. Outro fato que leva à opção de jogos infinitos, como os apresentados neste artigo, em detrimento da visão finita, reside na velocidade com a qual os agentes acreditam que o horizonte chega: velocidades lentas levam à opção de jogos infinitos. Tais justificativas são observadas também em processos políticos, daí a opção pela apresentação dos modelos infinitos, na explicação.

${ }^{11}$ Wolf (2008) mostra que, na Câmara dos Deputados do Brasil, durante a $52^{\text {a Legislatura }}$ (2003-2006), a aliança entre os políticos permaneceu estável, corroborando de certa forma a proposição dos teóricos defensores da estabilidade e, por consequência, do logrolling benéfico.

${ }^{12}$ Pretendemos aqui apresentar modelos teóricos sobre essa questão. Para uma explanação empírica a favor da estabilidade, o leitor pode consultar, por exemplo, Stratmann (1992), o qual, por meio 
de um modelo econométrico, argumenta que, caso uma minoria consiga arrebatar para si novos membros, a ponto de conquistar seus objetivos, esse resultado só pode ser fruto de organização, o que, para ele, quer dizer que as trocas são sempre organizadas e estáveis.

${ }^{13}$ A despeito de ser um defensor da troca de votos como meio que capte as intensidades das preferências dos indivíduos, Tullock (1970) afirma que, graças à possibilidade de barganha entre dois ou mais indivíduos, a possibilidade de trocas é baixa.

${ }^{14}$ Um resultado semelhante é obtido por Shepsle e Weingast (1981), apesar de fazerem uso de metodologia diferente. Para eles, o logrolling é indutor de desequilíbrio, sendo as instituições as grandes responsáveis por uma estabilidade no processo decisório como um todo. A título de exemplo, para eles, o simples fato de votações de comitês de menor importância serem precedidas por votações de comitês de grande importância, somado a um sistema no qual um projeto passaria, antes de ir a plenário, por um "analista" de regras para certificação, seria de grande valia para gerar estabilidade ao processo em questão.

${ }^{15}$ Como na formulação do exemplo anterior.

${ }^{16}$ Para a prova, cf. Osborne e Rubinstein (1994). 
AUSTEN-SMITH, David; BANKS, Jeffrey S. Positive political theory I: Collective preference. Ann Arbor: University of Michigan Press, 2000. 208 p.

AUSTEN-SMITH, David; BANKS, Jeffrey S. Positive political theory II: Strategy \& structure. Ann Arbor: University of Michigan Press, 2005. 454 p.

ARROW, Kenneth J. Social choice and individual values. 2. ed. New Haven: Yale University Press, 1970 [1951]. $144 \mathrm{p}$.

BLACK, Duncan. The theory of committees and elections. 2. ed. Norwell: Kluwer Academic Publishing, 1998 [1958]. 512 p.

BERNHOLZ, Peter. Logrolling, Arrow paradox and cyclical majorities. Public Choice, v. 15, p. 87-95, Summer 1973.

BERNHOLZ, Peter. On the stability of logrolling outcomes in stochastic games. Public Choice, v. 33 , n. 3, p. 65-82, 1978.

BRADY, Gordon L.; SELDON, Arthur; TULLOCK, Gordon. Falhas de governo: Uma introdução à teoria da escolha pública. Rio de Janeiro: Instituto Liberal, $2005.187 \mathrm{p}$.
BUCHANAN, James M.; TULLOCK, Gordon. The calculus of consent: Logical foundations of constitutional democracy. Indianapolis: Liberty Fund., 1990 [1962]. 337 p. (The selected works of Gordon Tullock v. 2).

CARRUBA, Clifford J.; VOLDEN, Craig. Coalitional politics and logrolling in legislative institutions. American Journal of Political Science, Bloomington, v. 44, n. 2, p. 261-277, apr. 2000.

CARVAlHo, Márcio André de. How logrolling can explain the failure o the government coalition in Brazil. Revista de Administração Pública, Rio de Janeiro, v. 40, n. 5, p. 865-882, Sept./Oct., 2006.

COLEMAN, James $\mathrm{S}$. The possibility of a social welfare function: Reply. The American Economic Review, v. 57, n. 5, p. 1311-1317, Dec. 1967.

DOWNS, Anthony. Uma teoria econômica da democracia. São Paulo: Edusp, 1999 [1957]. 330 p.

DUVERGER, Maurice. Political parties: Their organization and activity in the modern state. 3 . ed. London: Methuen, 1964. 480 p.
ENELOW, James M. Cycling and majority rule. In: MUELLER, Dennis C. (Org.). Perspectives on public choice: A handbook. New York: Cambridge University Press, 1997. cap. 7, p. 149-162. GEHRLEIN, William V. Condorcet's paradox. Theory and Decision, v. 15, n. 2, p. 161-197, Jun. 1983.

HARDIN, Russel. Economic theories of the state. In: MUELLER, Dennis C. (Org.). Perspectives on public choice: A handbook. New York: Cambridge University Press, 1997. cap. 2, p. 21-35.

KOFORD, Keneth J. Gordon. Centralized vote-trading. Public Choice, New York, v. 39, n. 2, p. 245-268, 1982.

LIJPHART, Arend. Modelos de democracia: Desempenho e padrões de governo em 36 países. 3 ed. Rio de Janeiro: Civilização Brasileira, 2011. 389 p.

LIMONGI, Fernando; FIGUEIREDO, Argelina Cheibub. Executivo e Legislativo na nova ordem constitucional. Rio de Janeiro:

Editora FGV, 1999. 232 p.

LIMONGI, Fernando; FIGUEIREDO, Argelina Cheibub. Incentivos eleitorais, partidos e política orçamentária. Dados, Rio de Janeiro, v. 45, n. 2, p. 303344, jul. 2002.
MAY, Kenneth O. A set of independent necessary and sufficient conditions for simple majority decisions. Econometrica, v. 20, n. 4, p. 680-684, 1952.

MAY, Kenneth O. A note on the complete independence of the conditions for simple majority decision. Econometrica, v. 21, p. 172-173, 1953 .

MCKELVEY, Richard

D. Intransitivities in multidimensional voting models and some implications for agenda control. Journal of Economic Theory, Saint Louis, v. 12, n. 3, p. 472-482, Jun. 1976.

MUELLER, Dennis C. Constitutional public choice. In: MUELLER, Dennis C. (Org.). Perspectives on public choice: A handbook. New York: Cambridge University Press, 1997. cap. 6, p. 124-146.

MUELLER, Dennis C. Public choice III. 9. ed. New York: Cambridge University Press, 2009. 768 p.

MYERSON, Roger B. Game theory: Analysis of conflict. Cambridge, Mass.: Harvard University Press, $1991.568 \mathrm{p}$.

NICOLAU, Jairo. Sistemas eleitorais. 5. ed. Rio de Janeiro: Editora FGV, 2004. $111 \mathrm{p}$. 
OLSON, Mancur. The logic of collective action: Public goods and the theory of groups. Cambridge: Harvard University Press, 1971 [1965]. 186 p.

OSBORNE, Martin J.; RUBINSTEIN, Ariel. A course in game theory. Cambridge, Mass.: MIT Press, 1994. 352 p.

OSTROM, Elinor; WALKER, James. Neither markets nor states: Linking transformation processesin collective action arenas. In: MUELLER, Dennis C. (Org.). Perspectives on public choice: A handbook. New York: Cambridge University Press, 1997. cap. 1, p. 35-72.

PEREIRA, Carlos; MUELLER, Bernardo. Comportamento estratégico em presidencialismo de coalizão: As relações entre Executivo e Legislativo na elaboração do orçamento brasileiro. Dados, Rio de Janeiro, v. 45, n. 2, p. 265-301, jul. 2002.

PEREIRA, Carlos; MUELLER, Bernardo. Partidos fracos na arena eleitoral e partidos fortes na arena legislativa: A conexão eleitoral no Brasil. Dados, Rio de Janeiro, v. 46, n. 4, p. 735-771, dez. 2003.

PEYTON YOUNG, H. Group choice and individual judgments. In: MUELLER, Dennis C. (Org.). Perspectives on public choice: A handbook. New York: Cambridge University Press, 1997. cap. 9, p. 181-200.
SCHOFIELD, Norman.

Multiparty electoral politics. In: MUELLER, Dennis C.

(Org.). Perspectives on public choice: A handbook. New York:

Cambridge University Press, 1997. cap. 13, p. 271-295.

SHEPSLE, Kenneth A.; WEINGAST, Barry R. Structureinduced equilibrium and legislative choice. Public Choice, New York, v. 37, n. 3 , p. 503-519, 1981.

\section{SHEPSLE, Kenneth A.} Analyzing politics: Rationality, behavior, and institutions. 2. ed. Norton, 2010. 548 p.

STRATMANN, Thomas.

The effects of logrolling on congressional voting. The American Economic Review,

Nashville, v. 82, n. 5, p. 1162-1176, Dec. 1992.

STRATMANN, Thomas. Logrolling. In: MUELLER, Dennis C. (Org.). Perspectives on public choice: A handbook. New York: Cambridge University Press, 1997. cap. 15, p. 322-341.

TIDEMAN, T. Nicolau. Voting and the revelation of preferences for public activities. In: MUELLER, Dennis C. (Org.). Perspectives on public choice: A handbook. New York: Cambridge University Press, 1997. cap. 11, p. 226-244.

TULLOCK, Gordon. A simple algebraic logrolling model. The American Economic Review, Nashville, v. 60, n. 3, p. 419-426, June 1970.
TULLOCK, Gordon. Why so much stability? Public Choice, New York, v. 37, n. 2 p. 189-204, 1981.

WIETING JR., Hardy Lee.

Philosophical problems in majority rule and the logrolling solution. Ethics, Chicago, v. 76, n. 2, p. 85-101, Jan. 1966.

WOLF, F. 0 comportamento dos deputados na Câmara Federal: Uma abordagem de redes sociais. 2008. 123 f. Dissertação (Mestrado Acadêmico em Ciência Política) - Instituto de Ciência Política, Universidade de Brasília, Brasília, 2008.
Os autores agradecem os valiosos comentários feitos pelos pareceristas anônimos.epelos professores Claudio Cesar de Paiva e

Paulo Furquim de Azevedo

E-mail de contato dos autores: amauer@mit.edu edstrach@fclar.unesp.br

Artigo recebido em fevereiro de 2013 e aprovado em maio de 2013. 